\title{
Atherosclerotic plaque imaging by PET/CT; can inactive, active and mixed plaques be discerned?
}

\author{
E. E. van der Wall · J. D. Schuijf · J. W. Jukema • \\ J. J. Bax · A. van der Laarse
}

Received: 16 November 2008/Accepted: 16 November 2008/Published online: 5 December 2008

(C) The Author(s) 2008. This article is published with open access at Springerlink.com

\begin{abstract}
Atherosclerosis is one of the leading causes of morbidity and mortality in the world. Rupture of atherosclerotic plaques and formation of thrombi are the primary mechanisms of myocardial infarction or cerebrovascular accidents. Atherosclerosis is therefore a dynamic inflammatory disorder and the biological composition and inflammatory state of an atherosclerotic plaque, rather than the degree of stenosis or its size, are the major determinants of acute clinical events [1, 2]. Noninvasive techniques to detect vulnerable atherosclerotic plaque are critically needed. In recent years, radionuclide imaging [3-6], magnetic resonance imaging (MRI) [7-13], and computed tomography (CT) have been put forward as the most relevant imaging modalities to identify atherosclerotic vascular disease and the vulnerable plaque [14-30]. Positron emission tomography with fluorodeoxyglucose (FDG-PET) has become one of the advanced imaging approaches for the detection of vulnerable plaques [31]. Ogawa et al. [32] showed that macrophages are responsible for the accumulation of FDG in atherosclerotic lesions whereby FDG uptake is
\end{abstract}

Editorial comment to the paper by Wassélius et al. (DOI:10.1007/s10554-008-9366-5).

E. E. van der Wall $(\bowtie) \cdot$ J. D. Schuijf .

J. W. Jukema · J. J. Bax · A. van der Laarse Department of Cardiology, Leiden University Medical Center, Albinusdreef 2, 2333-ZA Leiden, The Netherlands e-mail: E.E.van_der_Wall@lumc.nl correlated with macrophage density. Because vulnerable plaques are rich in macrophages, FDG imaging should be useful for selective detection of such plaques. In recent years, multislice CT has been shown to provide excellent anatomical and morphological images both of the large vessels and the coronary arteries [18]. In addition, differences in plaque composition and distribution-both in acute coronary syndromes and stable coronary artery disease-can adequately be visualized with multislice-CT $[29,30]$.

Hybrid imaging with both PET and CT, being a combined functional and structural whole-body imaging modality, could therefore offer the optimal potential to characterize plaque composition $[33,34]$. Tatsumi et al. [35] showed in 85 patients who underwent FDG PET/CT imaging that FDG uptake was commonly depicted in the thoracic aortic wall. The FDG uptake site was mostly distinct from the calcification site and was located in areas of metabolic activity (i.e., macrophages) of atherosclerotic changes. Ben-Haim et al. [36] evaluated FDG uptake in atherosclerotic plaques in 50 asymptomatic patients. Repeat PET/CT studies were performed to assess changes in patterns of FDG uptake and CT calcifications. FDG-avid foci represent a dynamic process of transient inflammation, whereas CT calcifications indicate stable atherosclerosis. Hybrid imaging with PET/CT creates therefore incremental value over both imaging modalities alone. Rudd et al. [37] showed that atherosclerosis imaging with FDG-PET/CT was useful for tracking inflammation within plaques. 
The authors assessed the short-term reproducibility of PET/CT in peripheral artery disease. Twenty patients with vascular disease underwent PET/CT imaging of the iliac, femoral, and carotid arteries 90 min after FDG administration. Mean and maximum target-to-background ratios in the carotid, iliac, and femoral arteries were highly reproducible. It was suggested that mean target-to-background ratio could be used for tracking systemic arterial therapies, whereas the maximum target-to-background ratio proved to be optimal for detecting and monitoring local, plaque-based therapy.

In the present issue of the International Journal of Cardiovascular Imaging, Wasselius et al. [38] assessed atherosclerotic plaques in a large asymptomatic population stratified to age and sex. The authors analyzed 200 patients in four age-groups of 20-30, 40-50, 60-70 and 80-90 years old, who were referred for whole-body FDG-PET/CT-examination. Uptake of FDG in active, calcified inactive and mixed atherosclerotic plaques was assessed in eight defined vessel segments. There was a high correlation between the total number of cardiovascular risk factors and the number of FDG-accumulating active plaques as well as the number of CT-determined calcified inactive plaques. A significant difference in the number of plaques between all age-groups was observed except for active plaques in the age groups of 60-70 and 80-90 years. A remarkable finding was that mixed plaques were very rare, similar to previous findings [39], suggesting that plaque inflammation and calcification are indeed discrete temporal pathophysiological entities. In addition, high counts for active plaques generally were paralleled by high counts for inactive, calcified plaques. Furthermore, a decrease in the number of active plaques was also accompanied by decreases in inactive, calcified plaques. This finding suggests that the lesions detected in the walls of large arteries by FDG-PET represent inflammation associated with the early phases of atherosclerosis. Lastly, statin-treatment was associated with a significantly lower number of active plaques. Consequently, FDG-PET/CT imaging was able to assess total plaque burden of patients, to identify plaque composition, and to monitor medical treatment of inflamed atherosclerotic plaques.

In a recent study by the same group [40], it was shown that graft infection was a serious complication to vascular surgery. FDG uptake was assessed in vascular grafts in 2,045 patients with or without symptoms of graft infection. Of all 2,045 patients examined by PET/CT, 16 patients with synthetic aortic grafts were identified and reevaluated for FDG accumulation. High FDG uptake was found in 10 of 12 grafts in the patients who underwent open surgery and in one of four grafts in patients who underwent endovascular aneurysm repair. Uptake of FDG in vascular grafts was found in the vast majority of patients without graft infection, even a long time after surgery. The basis for the FDG accumulation could be the chronic inflammation known to occur on the surface of synthetic graft material. Accumulation of FDG appeared to be less prominent in endovascular grafts than in conventional grafts.

In summary, integrated PET/CT imaging is a powerful new noninvasive modality that offers the potential for refined diagnosis and management of the entire spectrum of cardiovascular atherosclerosis [41]. Using PET/CT imaging, plaque inflammation (active plaques) and calcification (inactive plaques) can be observed as discrete temporal pathophysiological entities. Combined PET/CT imaging may therefore be superior to the single use of both PET imaging and CT angiography in guiding pharmacological treatment, assisting in revascularization decisions, and evaluating therapeutic effects.

Open Access This article is distributed under the terms of the Creative Commons Attribution Noncommercial License which permits any noncommercial use, distribution, and reproduction in any medium, provided the original author(s) and source are credited.

\section{References}

1. Ben-Haim S, Israel O (2006) PET/CT for atherosclerotic plaque imaging. Q J Nucl Med Mol Imaging 50:53-60

2. van Lennep JE, Westerveld HT, van Lennep HW, Zwinderman AH, Erkelens DW, van der Wall EE (2000) Apolipoprotein concentrations during treatment and recurrent coronary artery disease events. Arterioscler Thromb Vasc Biol 20:2408-2413

3. Berman DS, Hachamovitch R, Shaw LJ et al (2006) Roles of nuclear cardiology, cardiac computed tomography, and cardiac magnetic resonance: assessment of patients with suspected coronary artery disease. J Nucl Med 47:74-82

4. van der Wall EE, Heidendal GA, den Hollander W, Westera G, Roos JP (1980) I-123 labeled hexadecenoic acid in comparison with thallium-201 for myocardial imaging in coronary heart disease. A preliminary study. Eur J Nucl Med 5:401-405 
5. Bavelaar-Croon CD, Kayser HW, van der Wall EE et al (2000) Left ventricular function: correlation of quantitative gated SPECT and MR imaging over a wide range of values. Radiology 217:572-575

6. Bavelaar-Croon CD, Pauwels EK, van der Wall EE (2001) Gated single-photon emission computed tomographic myocardial imaging: a new tool in clinical cardiology. Am Heart J 141:383-390

7. Tang T, Howarth SP, Miller SR et al (2006) Assessment of inflammatory burden contralateral to the symptomatic carotid stenosis using high-resolution ultrasmall, superparamagnetic iron oxide-enhanced MRI. Stroke 37: 2266-2270

8. Langerak SE, Vliegen HW, de Roos A et al (2002) Detection of vein graft disease using high-resolution magnetic resonance angiography. Circulation 105:328-333

9. van der Wall EE, van Dijkman PR, de Roos A et al (1990) Diagnostic significance of gadolinium-DTPA (diethylenetriamine penta-acetic acid) enhanced magnetic resonance imaging in thrombolytic treatment for acute myocardial infarction: its potential in assessing reperfusion (1990). Br Heart J 63:12-17

10. van Dijkman PR, van der Wall EE, de Roos A et al (1991) Acute, subacute, and chronic myocardial infarction: quantitative analysis of gadolinium-enhanced MR images. Radiology 180:147-151

11. van Rugge FP, Holman ER, van der Wall EE, de Roos A, van der Laarse A, Bruschke AV (1993) Quantitation of global and regional left ventricular function by cine magnetic resonance imaging during dobutamine stress in normal human subjects. Eur Heart J 14:456-463

12. Tulevski II, Hirsch A, Sanson BJ et al (2001) Increased brain natriuretic peptide as a marker for right ventricular dysfunction in acute pulmonary embolism. Thromb Haemost 86:1193-1196

13. Bax JJ, Lamb H, Dibbets P et al (2000) Comparison of gated single-photon emission computed tomography with magnetic resonance imaging for evaluation of left ventricular function in ischemic cardiomyopathy. Am J Cardiol 86:1299-1305

14. Pundziute G, Schuijf JD, Jukema JW et al (2007) Noninvasive assessment of plaque characteristics with multislice computed tomography coronary angiography in symptomatic diabetic patients. Diabetes Care 30: 1113-1119

15. Schuijf JD, Jukema JW, van der Wall EE, Bax JJ (2007) Multi-slice computed tomography in the evaluation of patients with acute chest pain. Acute Card Care 9:214-221

16. van Werkhoven JM, Schuijf JD, Jukema JW et al (2008) Anatomic correlates of a normal perfusion scan using 64slice computed tomographic coronary angiography. Am J Cardiol 101:40-45

17. Pundziute G, Schuijf JD, Jukema JW et al (2007) Prognostic value of multislice computed tomography coronary angiography in patients with known or suspected coronary artery disease. J Am Coll Cardiol 49:62-70

18. Schuijf JD, Pundziute G, Jukema JW et al (2006) Diagnostic accuracy of 64-slice multislice computed tomography in the noninvasive evaluation of significant coronary artery disease. Am J Cardiol 98:145-148
19. Schuijf JD, Wijns W, Jukema JW et al (2006) Relationship between noninvasive coronary angiography with multislice computed tomography and myocardial perfusion imaging. J Am Coll Cardiol 48:2508-2514

20. Jongbloed MR, Lamb HJ, Bax JJ et al (2005) Noninvasive visualization of the cardiac venous system using multislice computed tomography. J Am Coll Cardiol 45:749-753

21. Braun S, van der Wall EE, Emanuelsson S, Kobrin I (1996) Effects of a new calcium antagonist, mibefradil (Ro 40 5967), on silent ischemia in patients with stable chronic angina pectoris: a multicenter placebo-controlled study, The mibefradil international study group. J Am Coll Cardiol 27:317-322

22. Molhoek SG, Bax JJ, Bleeker GB et al (2004) Comparison of response to cardiac resynchronization therapy in patients with sinus rhythm versus chronic atrial fibrillation. Am J Cardiol 94:1506-1509

23. Juwana YB, Wirianta J, Suryapranata H, de Boer MJ (2007) Left main coronary artery stenosis undetected by 64-slice computed tomography: a word of caution. Neth Heart J 15:255-256

24. Wijpkema JS, Dorgelo J, Willems TP et al (2007) Discordance between anatomical and functional coronary stenosis severity. Neth Heart J 15:5-11

25. van de Wal RM, van Werkum JW, le Cocq d'Armandville MC et al (2007) Giant aneurysm of an aortocoronary venous bypass graft compressing the right ventricle. Neth Heart J 15:252-254

26. de Leeuw JG, Wardeh A, Sramek A, van der Wall EE (2007) Pseudo-aortic dissection after primary PCI. Neth Heart J 15:265-266

27. Schuijf JD, Pundziute G, Jukema JW et al (2007) Evaluation of patients with previous coronary stent implantation with 64-section CT. Radiology 245:416-423

28. Schuijf JD, Bax JJ, van der Wall EE (2007) Anatomical and functional imaging techniques: basically similar or fundamentally different? Neth Heart J 15:43-44

29. Henneman MM, Schuijf JD, Pundziute G et al (2008) Noninvasive evaluation with multislice computed tomography in suspected acute coronary syndrome: plaque morphology on multislice computed tomography versus coronary calcium score. J Am Coll Cardiol 52:216-222

30. Schuijf JD, Beck T, Burgstahler C et al (2007) Differences in plaque composition and distribution in stable coronary artery disease versus acute coronary syndromes; noninvasive evaluation with multi-slice computed tomography. Acute Card Care 9:48-53

31. Ben-Haim S, Kupzov E, Tamir A, Israel O (2004) Evaluation of $18 \mathrm{~F}-\mathrm{FDG}$ uptake and arterial wall calcifications using 18F-FDG PET/CT. J Nucl Med 45:1816-1821

32. Ogawa M, Ishino S, Mukai T et al (2004) (18)F-FDG accumulation in atherosclerotic plaques: immunohistochemical and PET imaging study. J Nucl Med 45: $1245-1250$

33. Chen W, Bural GG, Torigian DA, Rader DJ, Alavi A (2008) Emerging role of FDG-PET/CT in assessing atherosclerosis in large arteries. Eur $\mathrm{J}$ Nucl Med Mol Imaging. doi: 10.1007/s00259-008-9047-2

34. Okane K, Ibaraki M, Toyoshima H et al (2006) 18F-FDG accumulation in atherosclerosis: use of $\mathrm{CT}$ and MR 
co-registration of thoracic and carotid arteries. Eur J Nucl Med Mol Imaging 33:589-594

35. Tatsumi M, Cohade C, Nakamoto Y, Wahl RL (2003) Fluorodeoxyglucose uptake in the aortic wall at PET/CT: possible finding for active atherosclerosis. Radiology 229:831-837

36. Ben-Haim S, Kupzov E, Tamir A, Frenkel A, Israel O (2006) Changing patterns of abnormal vascular wall F-18 fluorodeoxyglucose uptake on follow-up PET/CT studies. J Nucl Cardiol 13:791-800

37. Rudd JH, Myers KS, Bansilal S et al (2008) Atherosclerosis inflammation imaging with 18F-FDG PET: carotid, iliac, and femoral uptake reproducibility, quantification methods, and recommendations. J Nucl Med 49:871-878
38. Wassélius J, Larsson S, Sundin A, Jacobsson H (2008) Assessment of inactive, active and mixed atherosclerotic plaques by (18)F-FDG-PET; an age group-based correlation with cardiovascular risk factors. Int $\mathrm{J}$ Cardiovasc Imaging. doi:10.1007/s10554-008-9366-5

39. Dunphy MP, Freiman A, Larson SM et al (2005) Association of vascular 18F-FDG uptake with vascular calcification. J Nucl Med 46:1278-1284

40. Wassélius J, Malmstedt J, Kalin B et al (2008) High 18FFDG uptake in synthetic aortic vascular grafts on PET/CT in symptomatic and asymptomatic patients. J Nucl Med 49:1601-1605

41. Di Carli MF, Dorbala S (2007) Cardiac PET-CT. J Thorac Imaging 22:101-116 